Sharif University of Technology
Scientia Iranica
SCIENTIA
I RAN I CA
http://scientiairanica.sharif.edu

\title{
Application of wavelet theory with denoising to estimate the parameters of an earthquake
}

\author{
A. Heidari*, J. Raeisi, and R. Kamgar \\ Department of Civil Engineering, Shahrekord University, Shahrekord, Iran.
}

Received 24 March 2018; received in revised form 24 December 2018; accepted 8 April 2019

\section{KEYWORDS}

Strong ground motion; Filter bank;

Wavelet;

Discrete wavelet;

Denoising;

Dynamic.

\begin{abstract}
In this paper, Strong Ground Motion (SGM) parameters are calculated using Discrete Wavelet Transform (DWT) in different kinds of soil with different magnitudes. The Main Earthquake Record (MER) is divided into approximation and detailed signals using wavelet transform with denoising. The high and low frequencies of MER are separated from each other. Previous studies have shown that the approximation signal has the greatest effect on dynamic response and is very similar to the main signal. Then, SGM parameters of the new signal are calculated by DWT decomposition. This process continues over five levels and, at each level, SGM parameters are calculated and compared with the MER. Its error percentage is then presented. In DWT with the denoising method, the curve becomes softer such that the calculation time reduces. Results show that the error percentage in the first two levels is less than $1 \%$ and for the third level, this index is less than $3 \%$. In addition, the reduction percentage of calculation time is $1 \%, 4 \%$, and $8 \%$, respectively, in the first to third levels. The best result is relative to the third decomposition level in which error value as well as computational time reduction is nearly $3 \%$ and $8 \%$.
\end{abstract}

(C) 2021 Sharif University of Technology. All rights reserved.

\section{Introduction}

The three main characteristics of Strong Ground Motion (SGM) for earthquake engineering applications are the amplitude, frequency, and duration of motion. Some SGM parameters can describe one of the main characteristics of the Main Earthquake Record (MER), while some of the parameters describe two or more of the mentioned characteristics. Much research has been conducted investigating seismic parameters of SGM and their features and effect on structures. For instance, in discussing the seismic performance of structures in relation to probable future earthquakes, the seismic evaluation of existing buildings and designing new structures based on determining earthquake inten-

\footnotetext{
*. Corresponding author.

E-mail address: heidari@sku.ac.ir (A. Heidari)
}

sity measures have received considerable attention [13]. Time history analysis is the most important tool for seismic designations based on performance [4-6].

The most important concern in seismic analysis is making a monolithic and effective relation between the intensity index and the real damage to structures. Thus, seismic performance can be conducted with higher accuracy [7]. Modeling ground movement can be effective for determining the SGM intensity on structures. Two kinds of models are available for SGM. The first is related to the ground motion parameter equation relevant to the earthquake source, intensity, amplitude, frequency content, and movement duration [8] and the other model is related to ground motion time series [9]. Time series models include source-based deterministic models, source-based stochastic models, site-based stochastic models, and hybrid models that combine deterministic and stochastic [10]. Sourcebased deterministic models can describe the physical processes of source, site response, and wave propa- 
gation [11]. Many physical and Stochastic Methods (SM) have been suggested for better representation of wave propagation and their high frequency content [1214]. The models performing according to SM based on source are calibrated from regions with different kinds of soil and can show frequency content higher than $0.2 \mathrm{~Hz}$ [15]. Source-based SM in near-fault earthquakes has been suggested; the modeling has been undertaken according to physical parameters and some ground motion features such as time and spectral features and rupture effects are properly determined [9]. This suggested model also contains some of the other models. For example, a white-noise filtered model $[16,17]$, applicable for describing the near-fault bandwidth, is used by the modified model function to better indicate the SGM amplitude.

In addition, other research has been conducted analyzing ground movement frequencies in near faults without additional pulse, in which two parameters of $T_{m}$ and $T_{0}$ have been considered for separating high- and low-frequency components in near-fault regions [18]. A new predictive model for $T_{m}$ has been developed based on the horizontal components of ground motions selected from the expanded NGAWest2 database [19]. The interested reader is referred to further studies about the kind of selected soil and its effect on ground motion in $[20,21]$.

One of the best methods for separating earthquake frequencies is wavelet transform [22-24]. Wavelet transform is a new tool for analyzing signals and can give earthquake time and frequency information at the same time [25]. Application of wavelets to processing earthquake records, separating diffraction from the record and compressing information available in the record are important issues. Time history analysis has been performed for seismic analysis and Fast Wavelet Transform (FWT) has been used for this purpose. For decomposing acceleration, two kinds of high- and low-pass filters have been used. For the most part, low-frequency waves have been used for analyzing earthquake records. Some of the earthquakes have been calculated using this method and its results have been compared with MER. This showed that using the FWT method has provided excellent transform results [26]. In the research, the MER has been modified using wavelet transform at two levels and the earthquake record has been denoised [27]. Kaveh and Mahdavi presented a simple and accurate method for spectral adaption of ground motion [28]. Initially, in this method, the main ground motions are decomposed into different levels using Discrete Wavelet Transform (DWT) and then every level is multiplied by a coefficient. Finally, using an optimization method, variables are determined so that the error between the target and response spectrums is the lowest possible value. There are several optimization methods which can be used to find the optimum solution of a problem [29-31]. Recently, Gholizadeh and Mohammadi [32] used neural network and meta-heuristic optimization algorithms to obtain a reliable seismic design of a steel structure.

Developing an appropriate wavelet network and replacing it by accurate analysis reduced the optimization time considerably, while the accuracy of operations did not decrease [22]. An application of DWT for damage detection of a framed structure subjected to strong earthquake excitation was described. Results showed the effectiveness of the DWT approach to damage detection in the framed structures [33]. Todorovska et al. predicted wavelet approximation of earthquake SGM goodness of fit for a database in terms of predicting nonlinear structural response using earthquake wavelet approximation. It was concluded that the development of strong motion records on a wavelet basis can be used to receive pulses from a strong motion record, as well as represent strong motion records as the sum of pulses with a relatively small number [34]. In addition, Haigh et al. investigated the dynamic behavior of geotechnical structures using wavelet analysis. Wavelet transform and its application to the problems of soil dynamics and earthquake engineering have also been discussed [35].

In this paper, SGM parameters have been investigated using DWT in four kinds of soil with different magnitudes. For this purpose, these parameters are calculated initially using earthquake records. Then, the MER is decomposed using DWT and its high and low frequencies are obtained, so that two signals including earthquake approximation and details are obtained. As previous studies indicated that the approximation signal has the greatest effect on dynamic response; similar to MER, it is used as a New Earthquake Record (NER) and SGM parameters are calculated from this NER again. At the next level, the approximation wave is decomposed again and two new signals including approximation and detail are obtained. Again, the approximation signal is considered as a NER, and SGM parameters are calculated. This work continues over five levels and SGM parameters of each NER are compared with MER. The Daubechies 4 mother wavelet [36] has been used for wavelet decomposition of the earthquake record. The earthquake record has been decomposed using a denoising method in discrete condition. This means that the number of record points has not been reduced and only high frequencies of the earthquake record have been omitted in each level and the earthquake record becomes softer. Although the number of MER points does not decrease in this method, in every decomposition level, the curve has become softer and the duration of calculations has been reduced. In every wavelet decomposition level, half the noise at the previous level of the wave has been omitted. Results showed that error percentage at the first two levels is less than $1 \%$ and for the third level is less than 
$3 \%$. In addition, the percentage error of decomposition at the fourth and fifth levels is more than $10 \%$ and less than $40 \%$, respectively. The calculation duration of SGM parameters has been reduced $8 \%$ in comparison with the calculation duration of MER. The best result is related to the third level of decomposition in which the error value and time reduction are $3 \%$ and $8 \%$, respectively. It should be noted that 28 earthquakes have been selected in this paper, so that they include different kinds of soil with different shear wave velocities, magnitudes and focal distances; also, the accuracy of using wavelet transform is recognized well in all 28 earthquakes at all 5 levels. It should be noted that the wavelet transform used in this study can be applied to any other earthquake record.

\section{Strong Ground Motion (SGM)}

Amplitude, frequency, and duration of motion are the three main characteristics of ground motion for earthquake engineering applications. Many parameters have been developed for determining the amplitude, frequency, and duration of SGM. Some of these parameters describe only one of the aforementioned characteristics. Three main ground characteristics, including amplitude, frequency content, and duration of movement, have been described briefly in the following. Amplitude parameters, parameters such as acceleration, velocity, or displacement, or all of them, can be determined using time history. Amplitude parameters describe only the peak amplitude for the unique cycle from the time history of ground motion. Frequency content parameters describe the distribution of ground motion amplitude at different frequencies. The frequency content of earthquake motion is largely dependent on these movements. Motion duration parameters have a considerable effect on earthquake destructiveness. The duration of SGM depends on the time required for releasing cumulated strain energy along a fault.

Peak Ground Acceleration (PGA) is the maximum recorded acceleration value in an earthquake. The maximum value of the recorded characteristic in the velocity-time graph of an earthquake is called the Peak Ground Velocity (PGV) and the maximum displacement in the ground surface obtained from the displacement-time graph is the Peak Ground Displacement (PGD). The ratio between $\mathrm{PGV}$ and $\mathrm{PGA}$ is shown with PVA. The Acceleration Spectral Intensity (ASI) is known as the spectral acceleration integral of SGM, whose value is usually between 0.1 and 0.5 seconds and which is used for expressing SGM magnitude. In addition, the Velocity Spectral Intensity (VSI) is the spectral velocity integral of the SGM and expresses SGM magnitude. The third or fifth large value of acceleration or velocity time history are the Sustained Maximum Acceleration (SMA) and Sustained Maximum Velocity (SMV) of the earthquake record, and indicate the frequency content of SGM. The A95 parameter shows the maximum value of earthquake acceleration related to $95 \%$ of Arias intensity. The root-mean-square acceleration $\left(a_{R M S}\right)$ expresses the average intensity of earthquake acceleration and can be determined as follows:

$$
a_{R M S}=\sqrt{\frac{1}{T_{d}} \int_{0}^{T_{d}}[s(t)]^{2} d t},
$$

where $s(t)$ represents the acceleration of ground motion and $T_{d}$ represents the duration of the SGM.

The root-mean-square velocity $\left(V_{R M S}\right)$ expresses the average intensity of the earthquake velocity and can be determined as follows:

$$
V_{R M S}=\sqrt{\frac{1}{T_{d}} \int_{0}^{T_{d}}[v(t)]^{2} d t}
$$

where $v(t)$ represents the velocity-time ground motion.

The root-mean-square displacement $\left(D_{R M S}\right)$ expresses the average intensity of earthquake displacement and can be determined as follows:

$$
D_{R M S}=\sqrt{\frac{1}{T_{d}} \int_{0}^{T_{d}}[d(t)]^{2} d t}
$$

where $d(t)$ represents the displacement-time ground motion.

The Arias intensity $\left(I_{a}\right)$ for every earthquake indicates the energy value taken by the structure expressed as follows [37]:

$$
I_{a}=\frac{\pi}{2 g} \int_{0}^{T_{d}}[s(t)]^{2} d t .
$$

The characteristic intensity $\left(I_{C}\right)$ has a linear relation with the structural failure index due to maximum deformations and attracted hysteretic energy and is determined as follows [38]:

$$
I_{C}=\left(a_{R M S}\right)^{\frac{3}{2}} \cdot \sqrt{T_{d}} .
$$

The specific energy density $\left(S_{E}\right)$ indicates the frequency content and amplitude parameter of the earthquake and is determined using:

$$
S_{E}=\frac{\beta_{s} \rho_{s}}{4} \int v^{2}(t) d t,
$$

where $\beta_{s}$ and $\rho_{s}$ represent the shear wave velocity and soil density of the sampling site, respectively. 
The Cumulative Absolute Velocity (CAV) indicated is the area under the absolute acceleration graph. CAV can be used to show structural failure potentiality (see [39]):

$$
C A V=\int_{0}^{t_{\max }}|s(t)| d t,
$$

where $t_{\max }$ is the total duration of ground motion.

The Housner intensity $\left(I_{H}\right)$ represents the input energy and is proportional with the square integral of ground acceleration. This index can be obtained as follows [40]:

$$
I_{H}=\frac{1}{t_{2}-t_{1}} \int_{t_{1}}^{t_{2}} s(t) d t
$$

where $I_{H}$ has been computed in the period range of $t_{1}=0.2$ to $t_{2}=2$ seconds.

In Table 1, ground motion characteristics described by the mentioned parameters are presented. According to Table 1, SGM parameters have been divided into three groups:

1. Amplitude parameters, parameters determined by the time history directly. To obtain them, we should have only one of the acceleration, velocity, or displacement graphs in terms of time and determine other parameters using a derivation on integration.
Amplitude parameters include PGA, PGV, PGD, and the ratio between PGV and PGA (PVA);

2. Parameters giving both frequency content and amplitude information of SGM. These parameters include root-mean-square acceleration, root-meansquare velocity, root-mean-square displacement, acceleration spectrum intensity, velocity spectrum intensity, SMA, SMV, Housner intensity, and specific energy density;

3. Parameters representing comprehensive information about amplitude, frequency content, and earthquake duration. This means that by using one of the Arias intensity, CAV, characteristic intensity parameters and A95 parameter, the general movement of SGM in terms of amplitude, frequency, and duration can be discussed.

\section{Wavelet transform}

The Continuous Wavelet Transform (CWT) is expressed by the following equation:

$$
C W T_{s}^{\psi}=\frac{1}{\sqrt{|a|}} \int s(t) \psi_{a, b}^{*}(t) d t .
$$

This equation is a function of two variables $a$ and $b$. Here, $b$ indicates translation, $a$ represents scale and is corresponding to a period. Index $*$ shows complex conjugate, and $s$ and $\psi$ are the main wave (earthquake

\begin{tabular}{|c|c|c|c|}
\hline \multirow{2}{*}{ Ground motion parameters } & \multicolumn{3}{|c|}{ Ground motion characteristics } \\
\hline & Amplitude & Frequency content & Duration of motion \\
\hline Peak Ground Acceleration (PGA) & $*$ & & \\
\hline Peak Ground Velocity (PGV) & $*$ & & \\
\hline Peak Ground Displacement (PGD) & $*$ & & \\
\hline Peak ground velocity/Peak ground acceleration (PVA) & & * & \\
\hline Root mean square acceleration $\left(a_{R M S}\right)$ & * & * & \\
\hline Root mean square velocity $\left(v_{R M S}\right)$ & $*$ & $*$ & \\
\hline Root mean square displacement $\left(D_{R M S}\right)$ & $*$ & $*$ & \\
\hline Acceleration Spectrum Intensity (ASI) & $*$ & $*$ & \\
\hline Velocity Spectrum Intensity (VSI) & $*$ & $*$ & \\
\hline Sustained Maximum Acceleration (SMA) & * & * & \\
\hline Sustained Maximum Velocity (SMV) & $*$ & $*$ & \\
\hline Housner intensity $\left(I_{H}\right)$ & * & $*$ & \\
\hline Specific energy density $\left(S_{E}\right)$ & $*$ & $*$ & \\
\hline A95 parameter (A95) & $*$ & $*$ & $*$ \\
\hline Arias intensity $\left(I_{a}\right)$ & $*$ & $*$ & $*$ \\
\hline Characteristic intensity $\left(I_{c}\right)$ & $*$ & $*$ & $*$ \\
\hline Cumulative absolute velocity (CAV) & $*$ & $*$ & $*$ \\
\hline
\end{tabular}
record) and mother wavelet, respectively. The mother

Table 1. Ground motion characteristics by Strong Ground Motion (SGM) parameters. 
expression has been used because all functions used for CWT originate from a main (mother) function. In other words, the mother wavelet is the main wave for producing other functions. All the functions $\psi_{a, b}^{*}$ derived from the mother function are called wavelet functions or daughter wavelets and can be determined as follows:

$$
\psi_{a, b}(t)=\psi\left(\frac{t-b}{a}\right) .
$$

DWT is a wavelet series sampled from CWT. The principals of DWT refer to a method named Sub-Band Coding (SBC) developed in 1976 [41]. The main idea of this method is similar to CWT, in which a timescale description from the discrete signal is represented using digital filters. In fact, the wavelet transform indicates the similarity between the wave frequency (scale) content and wavelet function in different scales. To calculate CWT, the desired window is contracted (or expanded) and is transferred and then, by multiplying it by the signal, the time integral is obtained. In DWT, filters with different frequencies are used for analyzing signals in different scales. By passing the signal through high- and low-pass filters, the different signals are analyzed. In discrete conditions, the signal resolution is controlled by filter operators and the scale varies using down-sampling or up-sampling. To calculate DWT coefficients, instead of the $a$ and $b$ values used in Eq. (8), they should be replaced by their discrete values $\left(a=a_{0}^{j}\right.$ and $\left.b=k a_{0}^{j} b_{0}\right)$ as follows:

$$
\psi_{j, k}(t)=\frac{1}{\sqrt{a_{0}^{j}}} \psi\left(\frac{t-k a_{0}^{j} b_{0}}{a_{0}^{j}}\right)
$$

If we simplify the above equation, one has:

$$
\psi_{j, k}(t)=a_{0}^{\frac{-j}{2}} \psi\left(a_{0}^{-j} t-k b_{0}\right) .
$$

By replacing the above equation, the DWT is determined as follows:

$$
D W T_{s}^{\psi}=\int_{-\infty}^{+\infty} s(t) \psi_{j, k}^{*}(t) d t .
$$

An applied method, namely SBC, on earthquake signals, has been used for signals in electrical engineering in previous studies [42].

In this paper, the mentioned method has been used for analyzing earthquake records for the first time in which the MER is divided into two parts of high and low frequencies. Low and high frequencies of an earthquake record are called approximation and detail, respectively. In DWT, low frequencies of an earthquake record are applied and the detailed part is ignored. Another SBC is applied for the approximation part divided into two parts of approximation and detail.

In Figure 1, decomposing the Sefidrood Dam record in Iran using DWT is shown. In the first level of MER, two signals A1 and D1 have been obtained, in

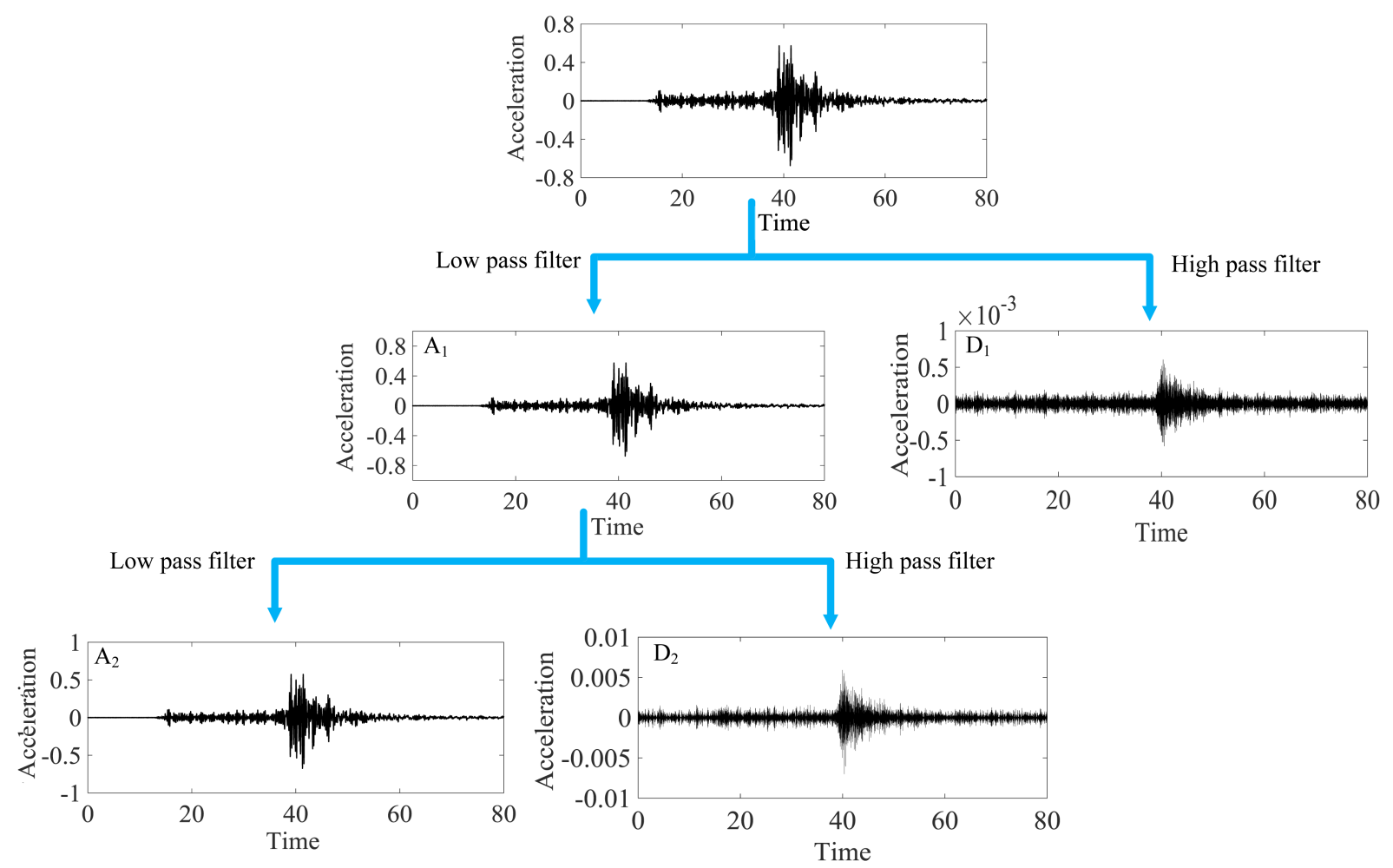

Figure 1. Schematic view of Discrete Wavelet Transform (DWT) of the Sefidrood Dam earthquake record. 
which A1 and D1 represent approximation and detail, respectively. Comparison between figures and MER shows that A1 is more similar to MER. Then, two signals A2 and D2 are obtained from A1. Signal A2 is more similar to A1. This process continues for five levels.

\section{Data bank}

In this study, 28 earthquake records have been used; these occurred in Iran from 1981 to 2013, as shown in Table 2 [43]. The value of the earthquake intensity of these records varied from 4.5 to 7.2 on the Richter scale. Distances to the center of the earthquake recording station were between 6 and $56 \mathrm{~km}$. These recorded earthquakes were classified into four categories in terms of the shear wave velocity of the soils. The shear wave velocity ranged from 165 to 1363 meters per second, respectively. These earthquakes are selected based on Chandler's classification [44]. According to this classification, the accelerograms are divided into three sets based on the ratio PGA/PGV, in which PGA and PGV show the PGA and velocity of the earthquake, respectively. The ratios (PGA/PGV) for the different earthquakes adopted in this paper are given in Table 2. According to Chandler's classification, all three types of earthquake sets have been used and studied in this paper. Hence, these earthquakes are good representatives to support a comprehensive analysis.

\section{Strong Ground Motion (SGM) with Discrete Wavelet Transform (DWT)}

In this study, SGM parameters have been determined in four kinds of soil with different magnitudes using DWT. For this purpose, at first, these parameters are obtained from MER. Then, the MER is decomposed using DWT and its high and low frequencies are obtained. Accordingly, two signals, including the detail and approximation of MER, are obtained. An approximate signal is used as a NER, and SGM parameters of NER are calculated again. In the next

Table 2. Information of earthquakes.

\begin{tabular}{|c|c|c|c|c|c|c|c|}
\hline $\begin{array}{l}\text { Number of } \\
\text { earthquake }\end{array}$ & $\begin{array}{c}\text { Earthquake's } \\
\text { name }\end{array}$ & $\begin{array}{c}\text { Station } \\
\text { name }\end{array}$ & $\begin{array}{l}\text { Station } \\
\text { code }\end{array}$ & Year & $\begin{array}{c}\text { PGA /PGV } \\
(\mathrm{g} \cdot \text { sec } / \mathbf{m})\end{array}$ & $\begin{array}{c}\text { Shear wave } \\
\text { velocity } \\
(\mathrm{m} / \mathrm{s})\end{array}$ & $\begin{array}{c}\text { Depth } \\
(\mathbf{k m})\end{array}$ \\
\hline 1 & Tabl & Tabl & TBL & 2008 & 1.44 & 931 & 6 \\
\hline 2 & Sadeh & Sadeh & SAD & 2008 & 2.92 & 854 & 7 \\
\hline 3 & Meimand & Meimand & MYN-A & 1994 & 2.40 & 881 & 8 \\
\hline 4 & Kolour & Kolour & KLR & 2006 & 6.32 & 860 & 9 \\
\hline 5 & Mousian & Mousian & MOS & 2008 & 2.13 & 472 & 32 \\
\hline 6 & Doubaran & Doubaran 1 & DBR1 & 2003 & 1.96 & 1363 & 10 \\
\hline 7 & Marak & Marak & MRK & 1997 & 0.73 & 559 & 10 \\
\hline 8 & Torbate-heidarieh & Torbate-heidarieh & TBH & 1997 & 2.24 & 306 & 10 \\
\hline 9 & Avaj & Avaj & AVJ & 2002 & 2.12 & 814 & 12 \\
\hline 10 & Ahar-Varzaghan & Khajeh & $\mathrm{KJH}$ & 2012 & 2.01 & 450 & 12 \\
\hline 11 & Abgarm & Abgarm & AGR & 2002 & 0.86 & 199 & 12 \\
\hline 12 & Fyn 1 & Fyn 1 & FYN1 & 2006 & 2.75 & 681 & 14 \\
\hline 13 & Noshahr & Noshahr & NSH & 2004 & 0.78 & 165 & 16 \\
\hline 14 & Roudsar & Roudsar & AUS & 2004 & 0.70 & 170 & 16 \\
\hline 15 & Jangal & Jangal & $\mathrm{JNG}$ & 2010 & 1.38 & 314 & 32 \\
\hline 16 & Ziveh & Ziveh & ZVH & 1998 & 0.91 & 304 & 26 \\
\hline 17 & Namin & Namin & NAM & 1997 & 4.45 & 1236 & 28 \\
\hline 18 & Boushehr 5 & Boushehr 5 & BSH5 & 2004 & 3.85 & 1267 & 30 \\
\hline 19 & Borazjan & Borazjan & BRZ & 2004 & 3.75 & 1329 & 30 \\
\hline 20 & Arkvaz-Malekshahi & Arkvaz-Malekshahi & AVZ & 2001 & 2.36 & 325 & 33 \\
\hline 21 & Minoudasht & Minoudasht & MDS-A & 2004 & 3.47 & 449 & 34 \\
\hline 22 & Ramian & Ramian & RMY & 2004 & 2.95 & 827 & 34 \\
\hline 23 & Bandargaz & Bandargaz & BGZ & 1999 & 2.38 & 347 & 14 \\
\hline 24 & Gorgan & Gorgan & GOG1 & 2004 & 3.72 & 291 & 34 \\
\hline 25 & Zarat & Zarat & ZRT & 1994 & 2.69 & 800 & 53 \\
\hline 26 & Roudbar 2 & Roudbar2 & RUB2-A & 1990 & 2.71 & 800 & 56 \\
\hline 27 & Babamonir & Babamonir & BBN & 2011 & 2.03 & 823 & 8 \\
\hline 28 & Ghir & Ghir & GHI-A & 1985 & 3.07 & 1099 & 48 \\
\hline
\end{tabular}


level, using DWT, the approximation signal obtained in the previous level is decomposed again and two new signals including approximation and detail are obtained. The approximation signal obtained in this level is a NER, and SGM parameters are calculated again. This process continues over five levels and the results obtained for the mentioned parameters are compared with MER. Results showed that for all parameters, the calculation error is less than $10 \%$ until the third level. For some of the parameters until the fourth or fifth level, the error can be ignored. In this study, the Daubechies 4 has been used for high and low frequencies of the earthquake record. The wavelet denoising method is used for decomposing the earthquake record. In this method, the number of points in every level does not decrease and only its noises are omitted. In Table 3 , some descriptions are presented for the signs applied in the figures and their specifications.

Table 4 presents error indices characteristics and also the method of their determination. Here, $E_{i}$ indicates the difference between the SGM parameters of NER and MER in each level.

\section{The main steps of methodology}

In main steps of calculating SGM parameters using wavelet transform are as follows:

(a) Determining SGM parameters of MER;

(b) Decomposing MER using DWT according to

Table 3. The abbreviations of signals decomposed in every level.

\begin{tabular}{ccl}
\hline Name & Abbreviation & $\begin{array}{c}\text { Wavelet decomposition } \\
\text { of earthquake record }\end{array}$ \\
\hline Main record & Main & Main earthquake wave \\
Level 1 & WTL1 & Decomposed in one level \\
Level 2 & WTL2 & Decomposed in two levels \\
Level 3 & WTL3 & Decomposed in three levels \\
Level 4 & WTL4 & Decomposed in four levels \\
Level 5 & WTL5 & Decomposed in five levels \\
\hline
\end{tabular}

Table 4. The abbreviation of error indices.

\begin{tabular}{ccl}
\hline Name & Abbreviation & $\begin{array}{c}\text { Wavelet decomposition } \\
\text { of earthquake record }\end{array}$ \\
\hline Main record & Main & Main earthquake wave \\
Level 1 & WTL1 & Decomposed in one level \\
Level 2 & WTL2 & Decomposed in two levels \\
Level 3 & WTL3 & Decomposed in three levels \\
Level 4 & WTL4 & Decomposed in four levels \\
Level 5 & WTL5 & Decomposed in five levels \\
\hline
\end{tabular}

Eq. (13) and separating the approximation and detail signal of MER;

(c) Considering approximation signal (A1) as a NER;

(d) Determining SGM parameters of NER;

(e) Decomposing of NER (A1) with DWT and determination of approximation record (A2);

(f) Considering approximation signal (A2) as a new NER and determining SGM parameters;

(g) Conducting steps (e) to (f) during 5 levels and determining SGM parameters at each level;

(h) Comparing SGM parameters at each level with an initial value in step (a);

(i) Determining error indices at all levels with respect to the initial value in step (a).

\section{Results and discussion}

In this section, SGM parameters are divided into terms of characteristics describing the ground in Table 2, and will be explained separately. In Figures 2-18, the parameters are investigated in all 28 earthquakes as well as the same parameter with 5 decomposed levels with denoising wavelet transform. All abbreviations of the considered parameters have been listed in the Appendix section.

Figures 2-5 indicate the parameters of PGA, PGV, PGD, and PVA, that can show ground motion amplitude. Figures 6-14 indicate the parameters of $a_{R M S}, v_{R M S}, D_{R M S}, A S I, V S I, S M A, S M V, I_{H}$, and $S_{E}$, which are able to describe the amplitude and frequency content of the ground. Figures 15-18 indicate parameters, representing three characteristics of amplitude, frequency content, and duration of SGM. These parameters include $I_{a}, \mathrm{~A} 95, I_{c}$, and CAV.

\subsection{Amplitude parameters}

Figure 2 indicates the PGA of MER and earthquakes decomposed into five levels, and Table 5 represents

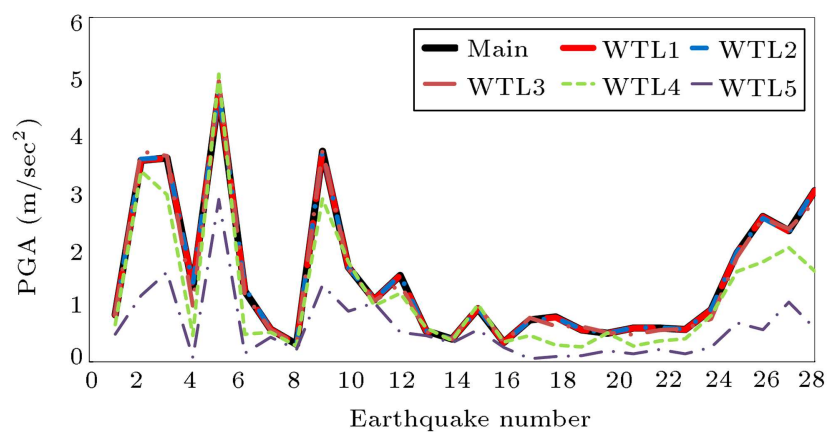

Figure 2. Peak Ground Acceleration (PGA) of Main Earthquake Record (MER) and New Earthquake Record (NER) of decomposition with Discrete Wavelet Transform (DWT). 
Table 5. Error indices for Strong Ground Motion (SGM).

\begin{tabular}{|c|c|c|c|c|c|c|c|c|c|c|c|c|c|c|c|}
\hline \multirow{2}{*}{ Parameter } & \multicolumn{3}{|c|}{ WTL1 } & \multicolumn{3}{|c|}{ WTL2 } & \multicolumn{3}{|c|}{ WTL3 } & \multicolumn{3}{|c|}{ WTL4 } & \multicolumn{3}{|c|}{ WTL5 } \\
\hline & MAE & MSE & RMSE & MAE & MSE & RMSE & MAE & MSE & RMSE & MAE & MSE & RMSE & MAE & MSE & RMSE \\
\hline$P G A$ & 0.42 & 0 & 0.75 & 1.5 & 0.05 & 2.23 & 7.14 & 0.10 & 10.70 & 32.70 & 21.56 & 46.43 & 83.14 & 135 & 82.25 \\
\hline$P G V$ & 0 & 0 & 0.03 & 0.01 & 0 & 0.05 & 0.15 & 0 & 0.28 & 0.63 & 0.01 & 1.68 & 2.18 & 0.13 & 3.54 \\
\hline$P G D$ & 0 & 0 & 0 & 0 & 0 & 0.01 & 0.02 & 0 & 0.03 & 0.03 & 0 & 0.08 & 0.25 & 0 & 0.87 \\
\hline$P V A$ & 0.04 & 0 & 0.02 & 0.06 & 0 & 0.09 & 0.26 & 0 & 0.37 & 1.37 & 0.05 & 2.38 & 4.91 & 0.59 & 7.69 \\
\hline$a_{R M S}$ & 0.02 & 0 & 0.13 & 0.09 & 0 & 0.19 & 0.71 & 0.01 & 1.11 & 3.40 & 0.38 & 6.15 & 8.44 & 1.32 & 11.49 \\
\hline$V_{R M S}$ & 0 & 0 & 0 & 0 & 0 & 0 & 0 & 0 & 0.01 & 0.03 & 0 & 0.04 & 0.26 & 0 & 0.84 \\
\hline$D_{R M S}$ & 0 & 0 & 0 & 0 & 0 & 0 & 0 & 0 & 0 & 0.01 & 0 & 0.02 & 0.10 & 0 & 0.50 \\
\hline$A S I$ & 0 & 0 & 0 & 0.05 & 0 & 0.20 & 1.03 & 0.02 & 1.38 & 11.76 & 3.12 & 17.65 & 55.11 & 55.90 & 74.77 \\
\hline$V S I$ & 0 & 0 & 0 & 0.03 & 0 & 0.09 & 0.27 & 0 & 0.44 & 1.60 & 0.07 & 2.69 & 6.37 & 1.02 & 10.12 \\
\hline$S M A$ & 0.25 & 0 & 0.43 & 1.90 & 0.14 & 3.77 & 13.2 & 6.86 & 26.19 & 32.69 & 21.86 & 46.75 & 62.93 & 77.80 & 88.20 \\
\hline$S M V$ & 0 & 0 & 0 & 0.01 & 0 & 0.02 & 0.15 & 0 & 0.25 & 0.39 & 0 & 0.51 & 1.50 & 0.04 & 2.10 \\
\hline$I_{H}$ & 0 & 0 & 0 & 0.02 & 0 & 0.11 & 0.04 & 0 & 0.15 & 0.38 & 0. & 0.60 & 3.26 & 0.67 & 8.16 \\
\hline$S_{E}$ & 0 & 0 & 0 & 0 & 0 & 0 & 0 & 0 & 0 & 0.02 & 0 & 0.05 & 0.17 & 0 & 0.38 \\
\hline$I_{a}$ & 0 & 0 & 0.01 & 0.15 & 0 & 0.31 & 1.19 & 0.04 & 2.23 & 7.15 & 1.62 & 12.71 & 16.85 & 8.95 & 29.92 \\
\hline$A 95$ & 0.58 & 0.03 & 1.76 & 1.73 & 0.08 & 2.88 & 9.45 & 2.58 & 16.08 & 11.78 & 4.24 & 20.59 & 28.5 & 19.61 & 42.28 \\
\hline$I_{c}$ & 0.01 & 0 & 0.04 & 0.34 & 0 & 0.76 & 1.97 & 0.12 & 3.39 & 11.78 & 4.24 & 20.59 & 28.50 & 19.61 & 42.28 \\
\hline$C A V$ & 0.06 & 0 & 0.26 & 1.27 & 0.05 & 2.24 & 12.05 & 2.53 & 15.91 & 54.60 & 48.66 & 69.76 & 138.51 & 284.43 & 168.77 \\
\hline
\end{tabular}

the statistical indices of these values. According to Table 5, their average error calculated from different methods is $0.39 \%, 1.26 \%, 5.95 \%, 33.56 \%$, and $135.13 \%$, respectively. In addition, the regression value in these five levels is $1,0.99,0.99,0.95$, and 0.85 . Therefore, if the acceptable error is considered less than $10 \%$, the wavelet decomposed in the third level can be used. Figure 2 shows that only for earthquake numbers 13 and 14, whose shear wave velocity is very low, can PGA decomposed at the fifth level be used.

Table 5 represents PGV statistical indices for MER and earthquakes decomposed into five levels and Figure 3 represents this parameter for all earthquakes and also five decomposed levels. Based on Table 5, the average error corresponding to levels 1 to 5 , determined according to different approaches, is $0.01 \%, 0.02 \%$, $0.14 \%, 0.57 \%$, and $1.95 \%$, respectively. The regression coefficient for levels 1 and 2 is 1 . This parameter is 0.99 for levels 3 and 4 and also 0.89 for level 5 . If acceptable error is considered less than $10 \%$, the wavelet decomposed in the fourth level can be used for calculating this parameter. It should be noted that the fourth level of decomposition means that high and low frequencies of MER have been decomposed four times using DWT. Figure 3 shows that for very low PGVs (less than $0.05 \mathrm{~m} / \mathrm{s}$ ), the wavelet decomposed in the fifth level can be used.

Figure 4 indicates that the PGD of MER and earthquakes decomposed in five levels, and Table 5 represents the statistical indices of these values. According

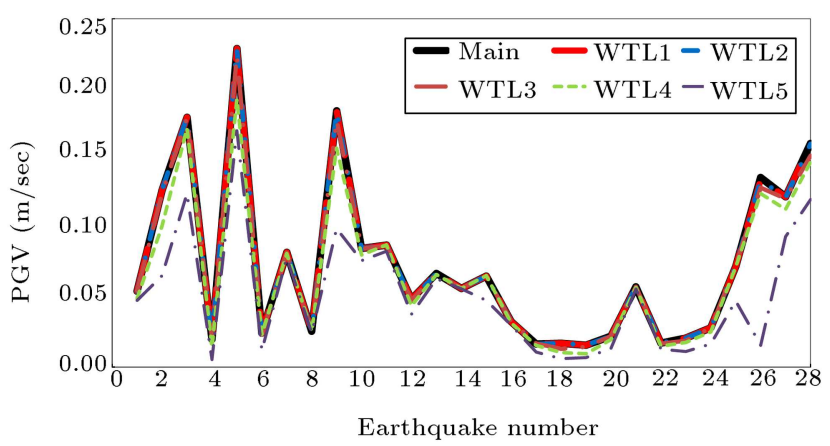

Figure 3. Peak Ground Velocity (PGV) of Main Earthquake Record (MER) and New Earthquake Record (NER) of decomposition with Discrete Wavelet Transform (DWT).

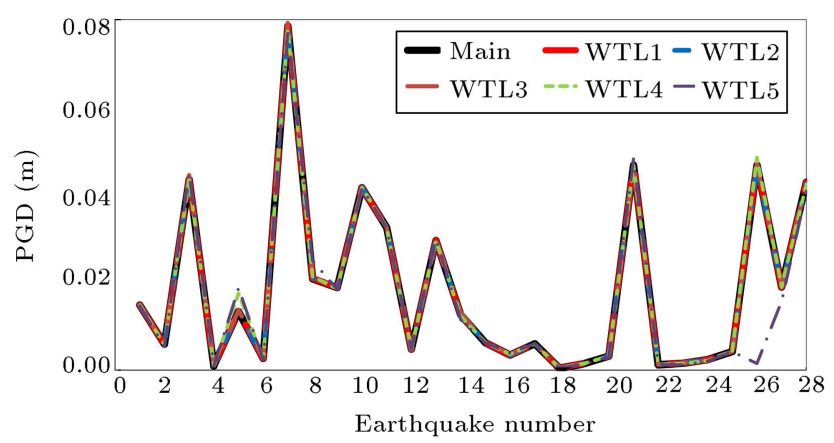

Figure 4. Peak Ground Displacement (PGD) of Main Earthquake Record (MER) and New Earthquake Record (NER) of decomposed with Discrete Wavelet Transform (DWT). 


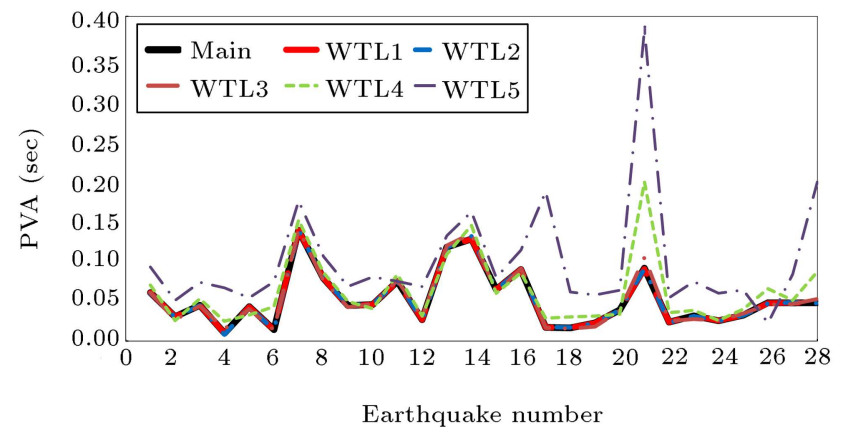

Figure 5. PVA of Main Earthquake Record (MER) and New Earthquake Record (NER) of decomposition with Discrete Wavelet Transform (DWT).

to Table 5, the average error calculated from different methods and regression value for levels 1 and 2 are 0 and 1, indicating the high accuracy of results for these two levels. In addition, the average error for levels 3,4 , and 5 is $0.01 \%, 0.03 \%$, and $0.37 \%$, respectively. Furthermore, for these levels, the regression value is 1, 1, 1, 0.99, and 0.91, respectively. Figure 4 shows that for all earthquakes (except earthquake number 26), PGD decomposed in the fifth level can be used.

\subsection{Frequency content}

Table 5 represents PVA statistical indices for MER and earthquakes decomposed into five levels and Figure 5 represents this parameter for all earthquakes and also five decomposed levels. According to Table 5, the average error calculated from different methods is varied increasingly, and the regression values in levels 1 to 5 for PVA are $1,0.99,0.99,0.86$, and 0.49 , respectively. This index is $0.02,0.05,0.21,1.26$, and 4.39 for these levels. Figure 5 shows that for all earthquakes, PVA decomposed in the third level can be used and the wavelets decomposed in the fourth and fifth levels are not very good.

\subsection{Amplitude and frequency content parameters}

Table 5 represents aRMS statistical indices for MER and earthquakes decomposed into five levels. According to Table 5, their average error was determined, according to different approaches, as 0.05\%, 0.09\%, $0.61 \%, 3.31 \%$, and $7.08 \%$, respectively. The regression coefficient for levels 1 and 2 is 1 . This index is very desirable for levels 3 and 4 as it is 0.99 and 0.91. For level 5 , the regression value is 0.83 . If acceptable error is considered less than $10 \%$, the wavelet decomposed in the third level implemented three times can be used. Figure 6 shows that only for earthquakes 13 and 14, in which their shear wave velocity is very low, can $a_{R M S}$ decomposed in the fifth level be used.

Table 5 represents $V_{R M S}$ statistical indices for MER and earthquakes decomposed into five levels and Figure 7 represents this parameter for all earthquakes

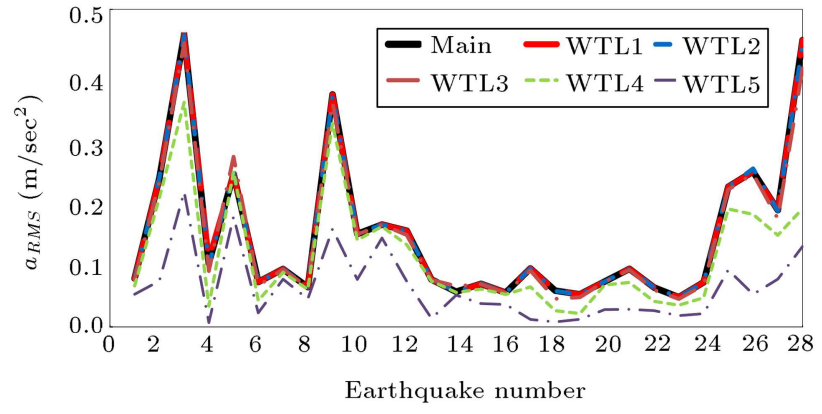

Figure 6. $a_{R M S}$ of Main Earthquake Record (MER) and New Earthquake Record (NER) of decomposition with Discrete Wavelet Transform (DWT).

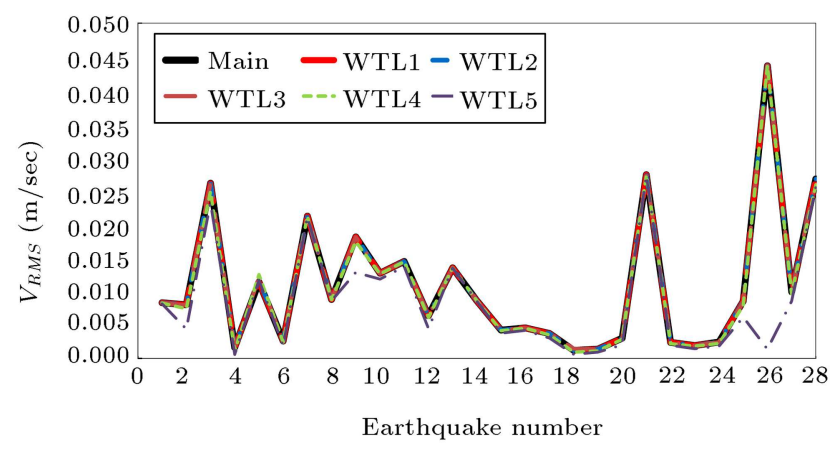

Figure 7. $V_{R M S}$ of Main Earthquake Record (MER) and New Earthquake Record (NER) of decomposition with Discrete Wavelet Transform (DWT).

and also five decomposed levels. Based on Table 5, the average error calculated from different methods is $0 \%, 0 \%, 0 \%, 0.02 \%$, and $0.36 \%$ for levels 1 to 5 , respectively, and for levels 1 to 3 the regression value is 1. In addition, it is 0.99 and 0.64 for levels 4 and 5. According to regression and error values it can be claimed that for calculating $V_{R M S}$ of earthquakes, except earthquakes with high shear wave velocity (more than $750 \mathrm{~m} / \mathrm{s}$ ), the wavelet decomposed in the fifth level can be used.

Table 5 represents $D_{R M S}$ statistical indices for MER and earthquakes decomposed into five levels according to Table 5. Their average error was determined, according to different approaches and regression coefficients for levels 1 to 3 , as 0 and 1 . The average error for levels 4 and 5 is $0.01 \%$ and $0.20 \%$, respectively. The regression coefficient in these two levels is 1 and 0.84 . Figure 8 shows that for all earthquakes (except for number 26), $D_{R M S}$ decomposed in the fifth level can be used.

According to Table 5 the average error of ASI was determined, according to different approaches, as $0.0 \%$, $0.08 \%, 0.81 \%, 10.84 \%$, and $61.92 \%$, respectively. The regression coefficient in these five levels is $1,1,0.99$, 0.99 , and 0.93 . Figure 9 shows that for all earthquakes, ASI decomposed in the third level can be used. It should be noted that a fourth level of decomposition 


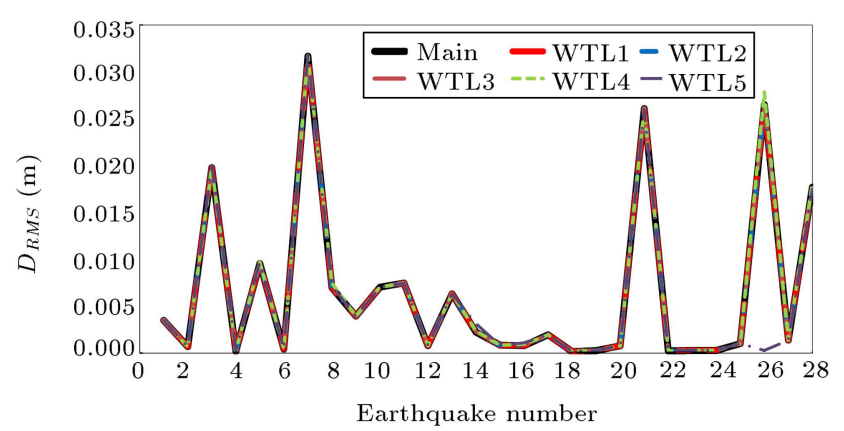

Figure 8. $D_{R M S}$ of Main Earthquake Record (MER) and New Earthquake Record (NER) of decomposition with Discrete Wavelet Transform (DWT).

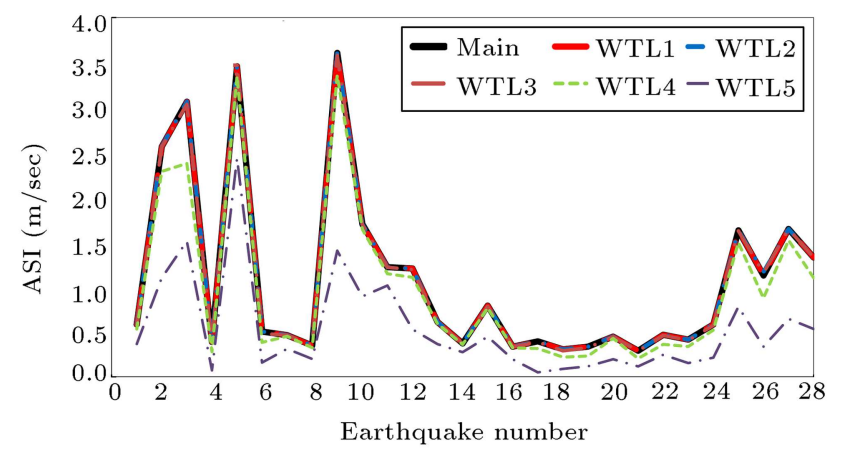

Figure 9. Acceleration Spectral Intensity (ASI) of Main Earthquake Record (MER) and New Earthquake Record (NER) of decomposition with Discrete Wavelet Transform (DWT).

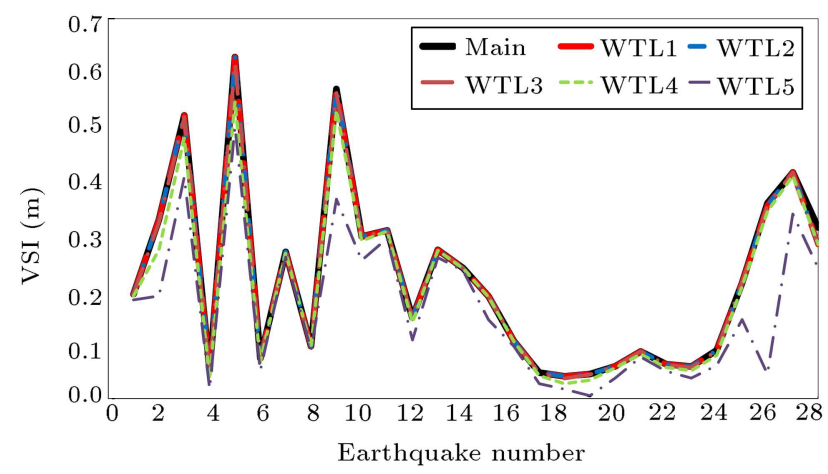

Figure 10. Velocity Spectral Intensity (VSI) of Main Earthquake Record (MER) and New Earthquake Record (NER) of decomposition with Discrete Wavelet Transform (DWT).

means that high and low frequencies of MER have been decomposed four times using DWT.

Table 5 represents VSI statistical indices for MER and earthquakes decomposed into five levels and Figure 10 represents this parameter for all earthquakes and also five decomposed levels. According to Table 5 , their average error was determined, according to different approaches, as $0.0 \%, 0.04 \%, 0.23 \%, 1.45 \%$, and $5.83 \%$, respectively. The regression coefficient in these five levels is $1,1,0.99,0.99$, and 0.91 . Based on

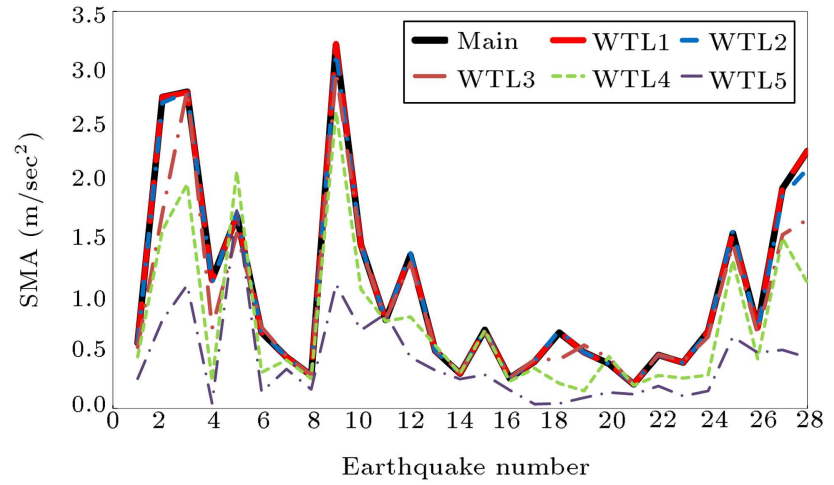

Figure 11. Sustained Maximum Acceleration (SMA) of Main Earthquake Record (MER) and New Earthquake Record (NER) of decomposition with Discrete Wavelet Transform (DWT).

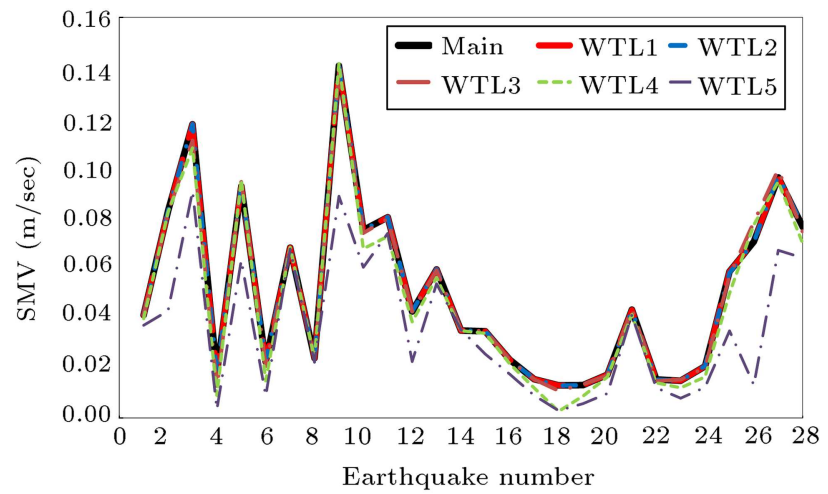

Figure 12. Sustained Maximum Velocity (SMV) of Main Earthquake Record (MER) and New Earthquake Record (NER) of decomposition with Discrete Wavelet Transform (DWT).

Figure 10, except for earthquakes 13 and 14 that have low shear wave velocities and wavelet decomposed in the fifth level, the fourth level wavelet can be used for calculating VSI.

According to Table 5, the average error of SMA was determined, according to different approaches, as $0.22,1.93,15.41,33.76$, and 76.31 percent, respectively, and the regression coefficient of SMA in levels 1 to 5 is $1,0.99,0.96,0.91$, and 0.70 . Figure 11 shows that for all earthquakes, SMA decomposed in the third level can be used.

Table 5 represents SMV statistical indices for MER and earthquakes decomposed into five levels and Figure 12 represents this parameter for all earthquakes and also five decomposed levels. According to Table 5 , their average error was determined, according to different approaches, as $0 \%, 0.01 \%, 0.13 \%, 0.33 \%$, and $1.21 \%$, respectively. The regression coefficient in levels 1 and 2 is 1 . The value of this index is 0.99 for levels 3 and 4 . In addition, it is 0.91 for level 5. If acceptable error is considered less than $10 \%$, the wavelet decomposed in the fourth level can 


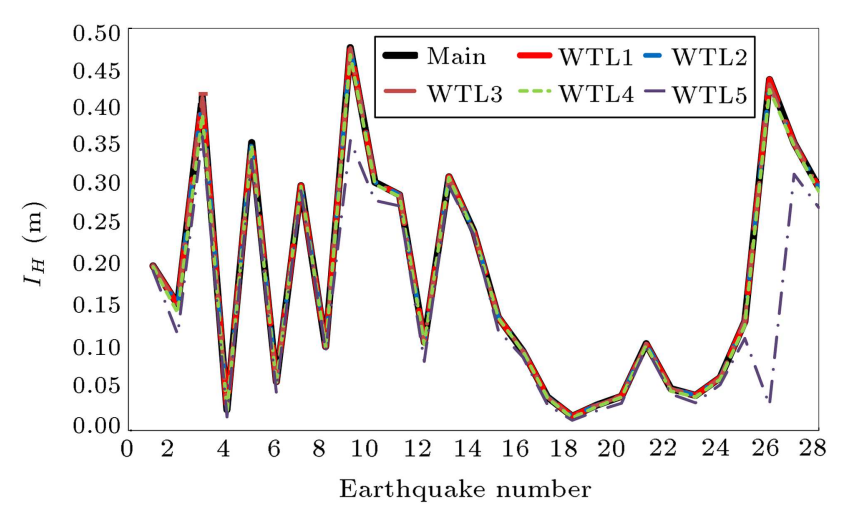

Figure 13. $I_{H}$ of Main Earthquake Record (MER) and New Earthquake Record (NER) of decomposition with Discrete Wavelet Transform (DWT).

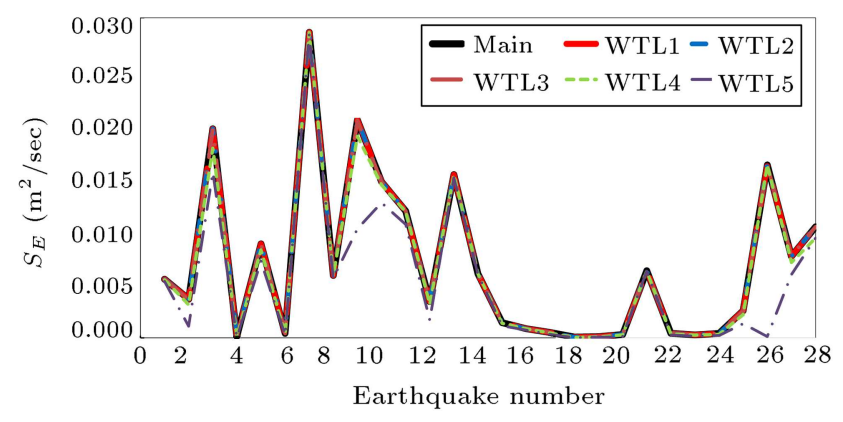

Figure 14. $S_{E}$ of Main Earthquake Record (MER) and New Earthquake Record (NER) of decomposition with Discrete Wavelet Transform (DWT).

be used for calculating SMV. It should be noted that the fourth level of decomposition means that high and low frequencies of the main earthquake wave have been decomposed four times using DWT.

According to Table 5 , their average error of $I_{H}$ was determined according to different approaches, as $0 \%, 0.04 \%, 0.06 \%, 0.32 \%$, and $4.03 \%$, respectively. The regression coefficient of $I_{H}$ in levels 1 to 5 is $1,1,1,0.99$, and 0.84 . Figure 13 shows that except for earthquakes 9,26 , and 27 that have high shear wave velocity, the fifth level wavelet can be used for calculating $I_{H}$.

Table 5 represents $S_{E}$ statistical indices for MER and earthquakes decomposed into five levels. According to Table 5, their average error was determined, according to different approaches, as 0\%,0\%, 0\%, $0.02 \%$, and $0.18 \%$, respectively. The regression coefficient in these five levels is $1,1,1,0.99$, and 0.89 . Figure 14 shows that except for earthquakes 3, 10 and 26 that have peak values, the fifth level wavelet can be used for calculating $S_{E}$.

Table 4 represents $I_{a}$ statistical indices for MER and earthquakes decomposed in 5 levels and Figure 15 represents this parameter for all earthquakes and also five decomposed levels. According to Table 5, the average error was determined, according to different approaches, as $0 \%, 0.1 \%, 1.15 \%, 7.16 \%$, and $18.57 \%$,

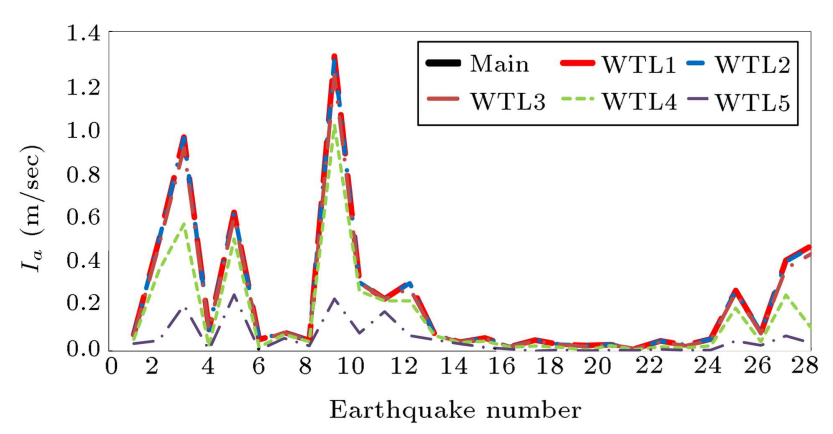

Figure 15. $I_{a}$ of Main Earthquake Record (MER) and New Earthquake Record (NER) of decomposition with Discrete Wavelet Transform (DWT).

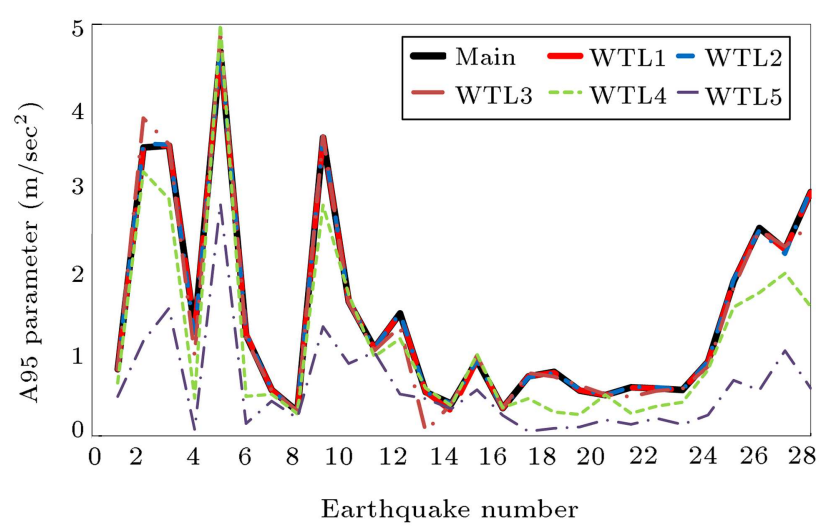

Figure 16. A95 parameter of Main Earthquake Record (MER) and New Earthquake Record (NER) of decomposition with Discrete Wavelet Transform (DWT).

respectively. The regression coefficient in these five levels is $1,1,0.99,0.96$, and 0.83 , and based on Figure 15, as the $I_{a}$ value is lower, the wavelets decomposed in the fourth and fifth levels can also be used, while for high values of $I_{a}$ only the third level decomposed wavelet can be used.

According to Table 5, the average error of the A95 parameter, determined according to different approaches, is $0.79 \%, 1.56 \%, 9.37 \%, 35.53 \%$, and $111.90 \%$, respectively, and the regression coefficient of A95 in these five levels is $1,0.99,0.99,0.95$, and 0.85 . As the A95 parameter is related to $95 \%$ of the Arias intensity, if the Arias intensity value is lower, wavelets decomposed in the fourth and fifth levels can also be used, while for high values of Arias intensity only the third level decomposed wavelet can be used. Figure 16 shows that for all earthquakes, A95 decomposed in the third level can be used.

According to Table 5, their average error of $I_{c}$ was determined, according to different approaches, as $0.01 \%, 0.36 \%, 1.82 \%, 12.23 \%$, and $30.79 \%$, respectively. The regression coefficient of $I_{c}$ in these five levels is $1,1,0.99,0.96$, and 0.84 . Furthermore, Figure 17 indicates the $I_{c}$ of MER and earthquakes decomposed into five levels. If acceptable error is considered less 


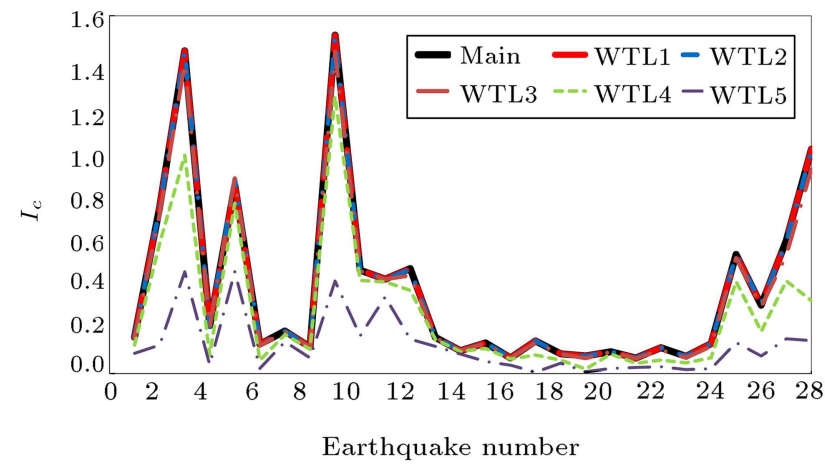

Figure 17. $I_{c}$ of Main Earthquake Record (MER) and New Earthquake Record (NER) of decomposition with Discrete Wavelet Transform (DWT).

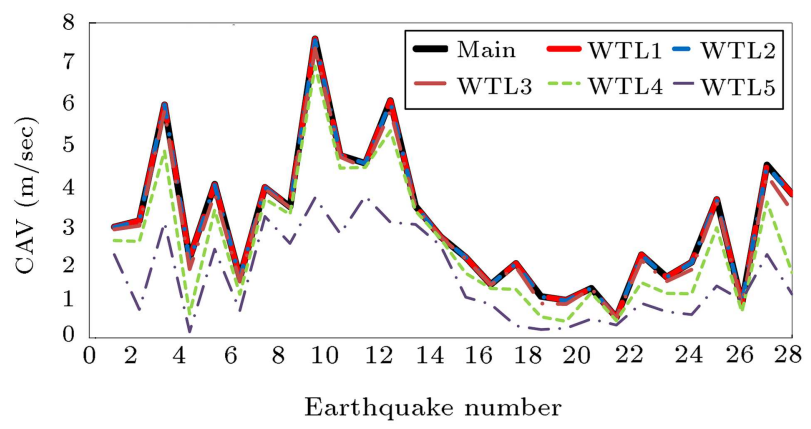

Figure 18. Cumulative Absolute Velocity (CAV) of Main Earthquake Record (MER) and New Earthquake Record (NER) of decomposition with Discrete Wavelet Transform (DWT).

than $10 \%$, wavelet decomposed in the third level can be used for calculating this parameter. It should be noted that the third level of decomposition means that high and low frequencies of the main earthquake wave have been decomposed three times using DWT.

Figure 18 indicates CAV of MER and earthquakes decomposed into five levels and Table 5 represents statistical indices of these values. The regression coefficient in these five levels is $1,1,0.99,0.96$, and 0.84 , respectively. According to Table 5, the average error was determined, according to different approaches, as $0.10 \%, 1.18 \%, 10.16 \%, 57.67 \%$, and $197.23 \%$, respectively. According to Figure 18, it can be claimed that for using this parameter in evaluating the failure of structures, the third level decomposed wavelet can be used.

The high and low frequencies are separated at each level using DWT. As a rule, at the first level, the largest frequencies with the lowest effect are eliminated. On the other hand, although the high frequencies are eliminated for higher levels at each level, the elimination of the high frequencies will remove a number of accelerogram data. According to the results of this study, it is clear that errors are insignificant until the third level. In other words, up to this level, the high frequencies have been eliminated three times and this is the reason for the occurred errors.

The studied SGM parameters (peak ground motion acceleration, peak ground motion velocity, Arias intensity, Housner intensity and etc.) are used to select some suitable earthquakes for dynamic analysis of structures. Therefore, eliminating the largest frequencies in each level reduces the number of accelerograms. It can decrease the required time for dynamic analysis especially for unconditionally stable methods such as the Linear Newmark method. In addition, by reducing the number of accelerograms, the responses of the structure cannot be computed at eliminating time. It should be noted that it does not affect the maximum responses of the structures, which are important [22].

\section{Conclusions}

Based on the results obtained in this paper, it can be concluded that Discrete Wavelet Transform (DWT) can be used to calculate Strong Ground Motion (SGM) parameters. DWT in the third level can be used to calculate all parameters of SGM with less error. The mean percentage of error indices in all parameters is $0.09 \%, 0.39 \%, 2.71 \%, 11.5 \%$, and $38.67 \%$, respectively, in levels 1 to 5 , respectively. Calculation time reductions due to the application of DWT are $1 \%, 4 \%, 8 \%, 9 \%$, and $10 \%$, respectively, for first to fifth levels, respectively. The mean regression in 1 to 5 levels is equal to $1,1,0.99,0.96$, and 0.82 , respectively. Application of the DWT method to calculate SGM parameters is used for the first time and there is no similar work in this field. The high and low frequencies are separated at each level by DWT. As a rule, at the first level, the largest frequencies with the lowest effect are eliminated. On the other hand, although the high frequencies are eliminated for higher levels at each level, the elimination of the high frequencies will remove a number of accelerogram data. According to the results of this study, it is clear that errors are insignificant until the third level. In other words, up to this level, the high frequencies have been eliminated three times and this is the reason for the occurred errors. These errors are the weak points in the wavelet theory. The studied SGM parameters are used to select some suitable earthquakes for dynamic analysis of structures. Therefore, eliminating the largest frequencies at each level reduces the number of accelerograms. It can decrease the required time for dynamic analysis, especially for unconditionally stable methods such as the Linear Newmark method. These characteristics are categorized as strong points for the wavelet theory. In addition, by reducing the number of accelerograms, the responses of the structure cannot be computed at eliminating time. It should be noted that it does not affect the maximum responses of the 
structures, which are important. In addition, some applications of the SGM parameters in earthquake and structural engineering are listed as follows:

The Peak Ground Acceleration (PGA) parameter is commonly used in structural design. It should be noted that for an earthquake with very high PGA and frequency content that has long, SGM duration, the damage value is greater than that of an earthquake with short SGM duration. The Peak Ground Velocity (PGV) parameter is an important tool for detecting the amount of damage or ground vibration intensity. It should be noted that maximum velocity gives a more precise characteristic for evaluating damage with respect to maximum acceleration. The Peak Ground Displacement (PGD) parameter is used to determine the value of damage. The PVA parameter is used to predict the average periods of earth motion for stiff and rocky ground. The Arias intensity is used as a criterion for measuring the magnitude of ground motion. This parameter mainly represents the amount of energy applied to the structure and is measured by the transient (unstable) earthquake waves to determine the magnitude of earthquake motion;

The characteristic intensity is defined as a criterion that is linearly related to the structural damage index due to the maximum change in structural deformation and absorbed hysteretic energy;

The Cumulative Absolute Velocity (CAV) is used to indicate the potential of structural damage. In other words, this parameter is an indicator of the energy applied to a structure by an earthquake and is directly related to structural damage;

The Housner intensity shows the capacity of ground motion to damage structures. It can be estimated as an average rate of total input of seismic energy per unit of mass during earthquake motion.

For the signals of the main earthquake and five decomposed levels for the earthquakes used in this paper, conducted in different kinds of soil, it can be claimed that:

(i) For stiff soils (with shear wave velocity less than $175 \mathrm{~m} / \mathrm{s}$ ), nearly all of the Main Earthquake Record (MER) parameters can be replaced by DWT parameters decomposed in the fifth level;

(ii) For rock and hard rock soil (with shear wave velocity more than $750 \mathrm{~m} / \mathrm{s}$ ), DWT in the third level can be used for calculating most parameters and the wavelet decomposed into four and five levels cannot be appropriate.

In addition, for the other parameters mentioned in Table 1 and their error and regression that had been investigated in five decomposed levels in Section 7 , the following claims can be made.

1. In all parameters that describe only ground motion amplitude:

- For PGA, the error value of the third level is less than $6 \%$;

- For PVA, the error value of the third level is less than $1 \%$;

- For PGV, the error value of the fourth level is less than $2 \%$;

- For PGD, the error value of the fifth level is less than $1 \%$.

2. For all parameters describing ground frequency content and amplitude:

- For Sustained Maximum Acceleration (SMA) the error value of the second level is less than $2 \%$;

- For $a_{R M S}$ and Acceleration Spectral Intensity (ASI), the error value of the third level is less than $1 \%$;

- For $S_{E}, I_{H}$, Sustained Maximum Velocity (SMV), $V_{R M S}$, the error value of the fourth level is less than $1 \%$;

- For Velocity Spectral Intensity (VSI), the error value of the fourth level is less than $2 \%$;

- For $D_{R M S}$, the error value of the fifth level is less than $1 \%$.

3. For parameters which describe three characteristics of ground motion:

- For $I_{a}$, the error value of the fourth level is less than $10 \%$;

- For $I_{c}$, the error value of the third level is less than $2 \%$;

- For A95, the error value of the third level is less than $10 \%$;

- For CAV, the error value of the second level is less than $2 \%$.

\section{Acknowledgments}

We would like to thank the Road, Housing and Urban Development Research Centre of Iran for providing earthquake records for this study.

\section{Nomenclature}

$\begin{array}{ll}S G M & \text { Strong Ground Motion } \\ M E R & \text { Main Earthquake Record } \\ S M & \text { Stochastic Method } \\ F W T & \text { Fast Wavelet Transform } \\ \text { NER } & \text { New Earthquake Record }\end{array}$


$P G A \quad$ Peak Ground Acceleration

$P G V \quad$ Peak Ground Velocity

$P G D \quad$ Peak Ground Displacement

$P V A \quad$ Ratio between PGV and PGA

ASI Acceleration Spectral Intensity

$V S I \quad$ Velocity Spectral Intensity

$S M A \quad$ Sustained Maximum Acceleration

$S M V \quad$ Sustained Maximum Velocity

$a_{R M S} \quad$ Root-Mean-Square acceleration

$V_{R M S} \quad$ Root-Mean Square velocity

$D_{R M S} \quad$ Root-Mean Square displacement

$I_{a} \quad$ Arias intensity

$I_{C} \quad$ Characteristic intensity

$S_{E} \quad$ Specific energy density

$C A V \quad$ Cumulative Absolute Velocity

$I_{H} \quad$ Housner intensity

DWT Discrete Wavelet Transform

$C W T$ Continuous Wavelet Transform

\section{References}

1. Kostinakis, K., Fontara, I.K., and Athanatopoulou, A.M. "Scalar structure-specific ground motion intensity measures for assessing the seismic performance of structures: a review", Journal of Earthquake Engineering, 22(4), pp. 630-665 (2018).

2. Bradley, B.A. "A generalized conditional intensity measure approach and holistic ground-motion selection", Earthquake Engineering \& Structural Dynamics, 39(12), pp. 1321-1342 (2010).

3. Kamgar, R., Samea, P., and Khatibinia, M. "Optimizing parameters of tuned mass damper subjected to critical earthquake", The Structural Design of Tall and Special Building, 27(7), p. e1460 (2018).

4. Kamgar, R. and Rahgozar, R. "A simple method for determining the response of linear dynamic systems", Asian Journal of Civil Engineering, 17(6), pp. 785-801 (2016).

5. Hung, C.C. and Lu, W.T. "A performance-based design method for coupled wall structures", Journal of Earthquake Engineering, 21(4), pp. 579-603 (2017).

6. Peres, R., Bento, R., and Castro, J.M. "Nonlinear static seismic performance assessment of plan irregular steel structures", Journal of Earthquake Engineering (2018). DOI: https://www. tandfonline. com/doi/abs/10.1080/13632469.2018.1469438

7. Ye, L., Ma, Q., Miao, Z., et al. "Numerical and comparative study of earthquake intensity indices in seismic analysis", The Structural Design of Tall and Special Buildings, 22(4), pp. 362-381 (2013).
8. Rathje, E.M., Faraj, F., Russell, S., et al. "Empirical relationships for frequency content parameters of earthquake ground motions", Earthquake Spectra, 20(1), pp. 119-144 (2004).

9. Dabaghi, M. and Der Kiureghian, A. "Stochastic model for simulation of near-fault ground motions", Earthquake Engineering \& Structural Dynamics, 46(6), pp. 963-984 (2017).

10. Graves, R.W. and Pitarka, A. "Broadband groundmotion simulation using a hybrid approach", Bulletin of the Seismological Society of America, 100(5A), pp. 2095-2123 (2010).

11. Day, S.M., Gonzalez, S.H., Anooshehpoor, R., et al. "Scale-model and numerical simulations of nearfault seismic directivity", Bulletin of the Seismological Society of America, 98(3), pp. 1186-1206 (2008).

12. Atkinson, G.M. and Silva, W. "Stochastic modeling of California ground motions", Bulletin of the Seismological Society of America, 90(2), pp. 255-274 (2000).

13. Motazedian, D. and Atkinson, G.M. "Stochastic finitefault modeling based on a dynamic corner frequency", Bulletin of the Seismological Society of America, 95(3), pp. 995-1010 (2005).

14. Halldorsson, B. and Papageorgiou, A.S. "Calibration of the specific barrier model to earthquakes of different tectonic regions", Bulletin of the Seismological Society of America, 95(4), pp. 1276-1300 (2005).

15. Halldórsson, B., Mavroeidis, G.P., and Papageorgiou, A.S. "Near-fault and far-field strong ground-motion simulation for earthquake engineering applications using the specific barrier model", Journal of Structural Engineering, 137(3), pp. 433-444 (2011).

16. Rezaeian, S. and Der Kiureghian, A. "Simulation of synthetic ground motions for specified earthquake and site characteristics", Earthquake Engineering \& Structural Dynamics, 39(10), pp. 1155-1180 (2010).

17. Rezaeian, S. and Der Kiureghian, A. "Simulation of orthogonal horizontal ground motion components for specified earthquake and site characteristics", Earthquake Engineering \& Structural Dynamics, 41(2), pp. 335-353 (2012).

18. Yang, D. and Wang, W. "Nonlocal period parameters of frequency content characterization for near-fault ground motions", Earthquake Engineering \& Structural Dynamics, 41(13), pp. 1793-1811 (2012).

19. Du, W. "An empirical model for the mean period (Tm) of ground motions using the NGA-West2 database", Bulletin of Earthquake Engineering, 15(7), pp. 26732693 (2017).

20. Zhang, N., Gao, Y., and Pak, R.Y. "Soil and topographic effects on ground motion of a surficially inhomogeneous semi-cylindrical canyon under oblique incident SH waves", Soil Dynamics and Earthquake Engineering, 95, pp. 17-28 (2017). 
21. Rong, M., Wang, Z., Woolery, E.W., et al. "Nonlinear site response from the strong ground-motion recordings in western China", Soil Dynamics and Earthquake Engineering, 82, pp. 99-110 (2016).

22. Salajegheh, E. and Heidari, A. "Time history dynamic analysis of structures using filter banks and wavelet transforms", Computers \& Structures, 83(1), pp. 5368 (2005).

23. Heidari, A., Raeisi, J., and Kamgar, R. "Application of wavelet theory in determining of strong ground motion parameters", International Journal of Optimization in Civil Engineering, 8(1), pp. 103-115 (2018).

24. Gholizadeh, S. and Samavati, O.A. "Structural optimization by wavelet transforms and neural networks", Applied Mathematical Modelling, 35(2), pp. 915-929 (2011).

25. Heidari, A. and Salajegheh, E. "Wavelet analysis for processing of earthquake records", Asian Journal of Civil Engineering, 9(5), pp. 513-524 (2008).

26. Salajegheh, E. and Heidari, A. "Optimum design of structures against earthquake by wavelet neural network and filter banks", Earthquake Engineering \& Structural Dynamics, 34(1), pp. 67-82 (2005).

27. Ansari, A., Noorzad, A., Zafarani, H., et al. "Correction of highly noisy strong motion records using a modified wavelet de-noising method", Soil Dynamics and Earthquake Engineering, 30(11), pp. 1168-1181 (2010).

28. Kaveh, A. and Mahdavi, V.R. "A new method for modification of ground motions using wavelet transform and enhanced colliding bodies optimization", Applied Soft Computing, 47, pp. 357-369 (2016).

29. Kaveh, A., Rastegar Moghaddam, M., and Khanzadi, M. "Efficient multi-objective optimization algorithms for construction site layout problem", Scientia Iranica, 25(4), pp. 2051-2062 (2018).

30. Dabbagh, H., Ghodrati Amiri, G., and Shaabani, Sh. "Modal data-based approach to structural damage identification by means of imperialist competitive optimization algorithm", Scientia Iranica, 25(3), pp. 1070-1082 (2018).

31. Heidari, A. and Raeisi, J. "Optimum design of structures against earthquake by simulated annealing using wavelet transform", Soft Computing in Civil Engineering, 2(4), pp. 23-33 (2018).

32. Gholizadeh, S. and Mohammadi, M. "Reliability-based seismic optimization of steel frames by meta-heuristics and neural networks", ASCE-ASME Journal of Risk and Uncertainty in Engineering Systems, Part A: Civil Engineering, 3(1), pp. 04016013-1 (2017). DOI: http://dx.doi.org/10.1061/AJRUA6.0000892

33. Pnevmatikos, N.G. and Hatzigeorgiou, G.D. "Damage detection of framed structures subjected to earthquake excitation using discrete wavelet analysis", Bulletin of Earthquake Engineering, 15(1), pp. 227-248 (2017).
34. Todorovska, M.I., Meidani, H., and Trifunac, M.D. "Wavelet approximation of earthquake strong ground motion-goodness of fit for a database in terms of predicting nonlinear structural response", Soil Dynamics and Earthquake Engineering, 29(4), pp. 742-751 (2009).

35. Haigh, S.K., Teymur, B., Madabhushi, S.P.G., et al. "Applications of wavelet analysis to the investigation of the dynamic behaviour of geotechnical structures", Soil Dynamics and Earthquake Engineering, 22(9-12), pp. 995-1005 (2002).

36. Daubechies, I. "The wavelet transform, time-frequency localization and signal analysis", IEEE Transactions on Information Theory, 36(5), pp. 961-1005 (1990).

37. Arias, A. "Measure of earthquake intensity", Massachusetts Inst. of Tech., Cambridge. Univ. of Chile, Santiago de Chile (1970).

38. Park, Y.J., Ang, A.H.S., and Wen, Y.K. "Seismic damage analysis of reinforced concrete buildings", Journal of Structural Engineering, 111(4), pp. 740757 (1985).

39. Kramer, S.L., Geotechnical Earthquake Engineering, Prentice Hall, New York (1996).

40. Housner, G.W. "Measures of severity of earthquake ground shaking", Proceedings of the First US National Conference on Earthquake Engineering, Ann Arbor, MI (1975).

41. Crochiere, R.E. "Digital signal processor: sub-band coding", Bell Labs Technical Journal, 60(7), pp. 16331653 (1981).

42. Woods, J.W., Subband Image Coding, Kluwer Academic Publishers, Dordrecht (1991).

43. Raeisi, J. "Investigating strong ground motion using wavelet theory for hydraulic structure in far fault", Master Science of Water and Hydraulic Structure, Shahrekord University, Iran (2017).

44. Gholizadeh, S. and Salajegheh, E. "Optimal seismic design of steel structures by an efficient soft computing based algorithm", Journal of Constructional Steel Research, 66(1), pp. 85-95 (2010).

\section{Biographies}

Ali Heidari obtained his BS degree from Isfahan University of Technology and his MS and PhD degrees in Civil Engineering from Shahid Bahonar University of Kerman. At present, he is Associate Professor at Shahrekord University and has published over 60 journal and conference papers. His professional research interests include earthquake engineering, concrete technology, structural optimization and dynamics of structures.

Jalil Raeisi obtained his BS and MS degrees in Civil Engineering from the Department of Civil Engineering 
at Shahrekord University, Shahrekord, Iran. He graduated in 2017 and, at present, is a researcher of Chaharmal and Bakhtiari Water and Wastewater Company. He has published 10 journal and conference papers. His research areas of interest include earthquake engineering, strong ground motion, structural optimization, water resources management and hydrology.

Reza Kamgar obtained his MS and $\mathrm{PhD}$ degrees in Civil engineering from the Department of Civil Engineering at Shahid Bahonar University of Ker- man, Kerman, Iran. He graduated in 2015 and, at present, is a faculty member of Shahrekord University, Shahrekord, Iran. His field of research includes dynamics of structures, earthquake engineering, finite element method, ductile design of steel structures, vibration control, tall buildings, soil-structure interaction, structural optimization, and soft computing methods. He has published 59 journal and conference papers, and 4 books. He also achieved first place in his undergraduate class for his MS and PhD degrees in 2012 and 2015, respectively. 